\title{
Identifying Cultural Traits of the Historic Kampong Ayer of Brunei Darussalam using Biomimetic Analysis
}

\author{
Gabriel Yit Vui Yong
}

Geography, Environment \& Development Programme, Faculty of Arts \& Social Sciences, Universiti Brunei Darussalam, Gadong, Brunei Darussalam

Manuscript received: July 16, 2021

Manuscript revised: August 25, 2021

Manuscript accepted: August 31, 2021

Date of publication: August 31, 2021.

Corresponding author:

Name:

Gabriel Yit Vui Yong

Email:

gabriel.yong@ubd.edu.bn

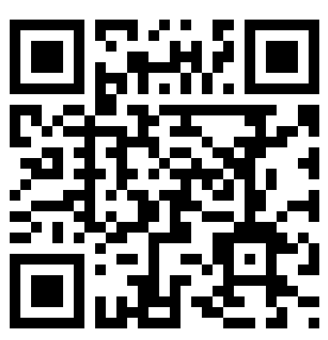

\begin{abstract}
Kampong Ayer is the cultural hearth of Brunei Darussalam. Once described as the Venice of the East, modernization has transformed this capital of the Brunei Sultanate into just another urban settlement, but located within the Sungai Brunei estuary. Its largely modern architecture and built environment has raised the question of whether it still holds any heritage value. This paper aims to provide an answer using the UNESCO World Heritage Site enlistment criteria as a guide. The study focusses on the relationship between people and environment (Criteria 5) to determine if they could be regarded as an outstanding example that is vulnerable to irreversible change. It employs a biomimetic approach to analysis as field surveys suggest the environment to be a prominent factor. The information used was gathered over the past decade through field work and dialogue with current and former residents. The study found a good degree of congruence between residents of Kampong Ayer and mangroves, the 'genius of place' in the Sg Brunei estuary. It also found processes and patterns typical of organismic, evolving systems. The study elucidated cultural traits that have survived through the evolution of Kampong Ayer over half a millennium. The paper also addresses sustainability issues using findings from biomimetic analysis.
\end{abstract}

Keywords: Kampong Ayer, biomimicry, cultural traits, 'genius of place', organismic.

\section{INTRODUCTION}

Kampong Ayer (KA), literally "water village", is the cultural hearth of Brunei Darussalam (for brevity, Brunei). It was the main city of the Brunei Sultanate before modernisation and transition to a nation state on land. The process has relegated the historic water-based settlement to be just one of many residential areas in the country. It has also systematically obliterated past architecture. KA is however still promoted as a cultural heritage in Brunei's nascent tourism program. The historic settlement is located in a section of the Sungai (Sg) Brunei estuary, facing the central business district (CBD) of the country's capital, Bandar Seri Begawan (BSB) to the north. Its geographical reference is Latitude $4^{\circ} 52^{\prime} 54^{\prime \prime} \mathrm{N}$ and Longitude $114^{\circ} 56^{\prime} 34^{\prime \prime} \mathrm{E}$.

Copyright (c) 2021 The Author(s).

(i) (2) This is an Open Access article distributed under the terms of the Creative Commons Attribution-ShareAlike 4.0 International (https://creativecommons.org/licenses/by-sa/4.0/) 


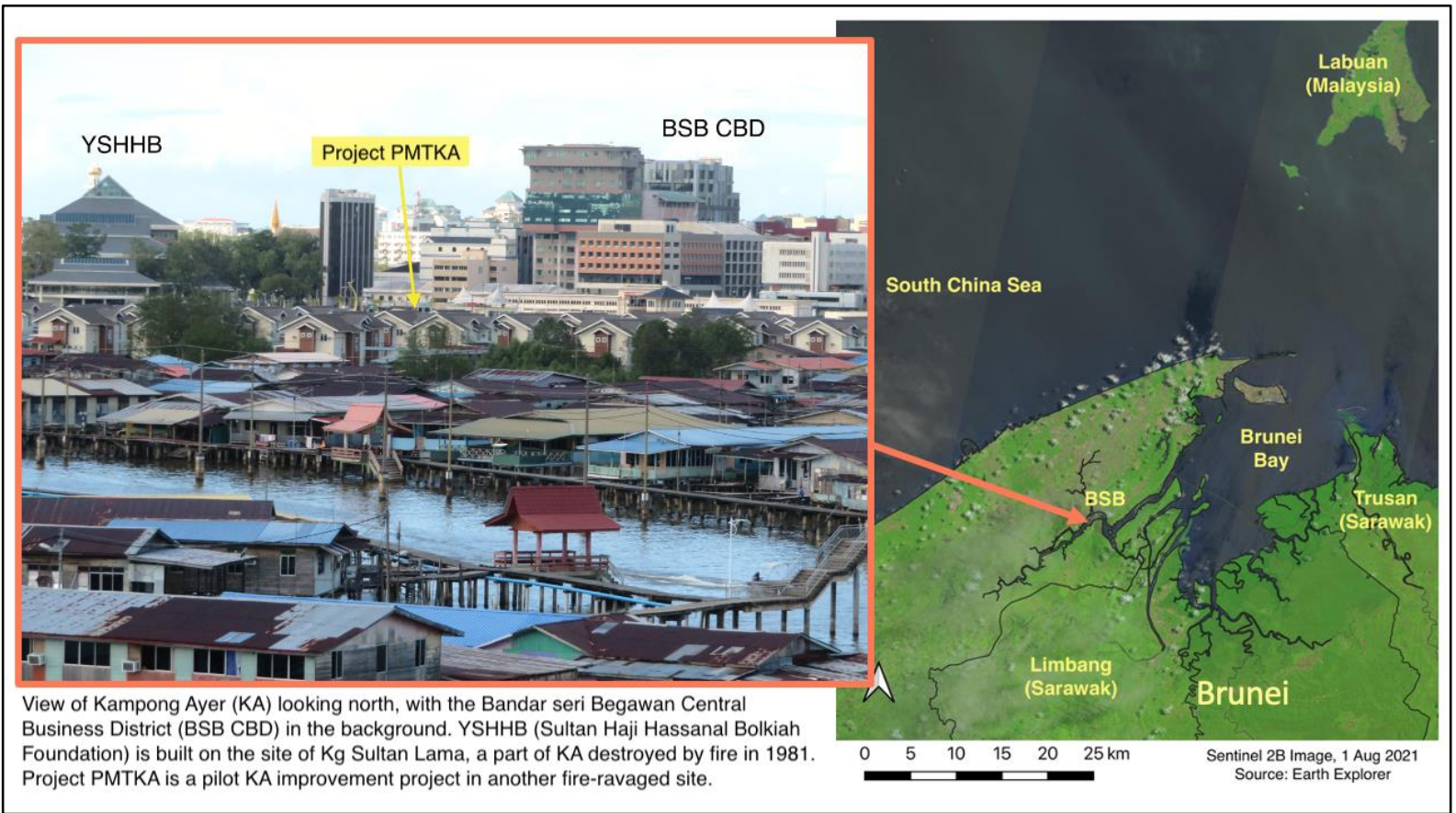

Fig. 1. Location and View of Kampong Ayer.

The impetus for this research stems from involvement in a series of consultative workshops in the BSB Masterplan development process in 2009-2010. It included a proposal to submit KA for consideration as a UNESCO World Heritage Site (WHS). While this would undoubtedly increase the visibility of BSB and boosts the development of its fledgling tourism industry and contribute to economic diversification, KA does not appear historic nor its architecture unique to be regarded as a global heritage. Of the 10 criteria (cr.) listed by UNESCO for enlistment, all except one are not applicable to KA. It does not a masterpiece of creative genius (cr.1); does not possess architecture, monuments or landscape of note (cr.2); is not a unique civilisation (cr.3); does not have structures, landscapes or technology that are significant in the history of humanity (cr.4), or associated with traditions, beliefs, artistic and literary works of outstanding universal significance. It is also not an area of superlative natural phenomenon (cr.7), as well as representative of major stages of the Earth's history (cr.8), significant ecosystems (cr.9) or habitats of endangered species (cr.10).

Cr.5 states that the site should be an "outstanding example of a traditional human settlement, landuse, or sea-use which is representative of a culture (or cultures), or human interaction with the environment especially when it has become vulnerable under the impact of irreversible change". KA is about 600 years old, but its architecture and built structure is largely modern (see Fig.1). It is however idiosyncratic in its morphology and texture, appearing engineered yet organic, lacking vitality but interspersed with pockets enterprise as well as decay. There are a number of spaces occupied only by stilts (of houses destroyed by fire), a few of which been rejuvenated, such as Project PMTKA (Perintis Menaik Taraf Kampung Ayer, or pilot project to upgrade KA) in Figure 1. An observant visitor venturing through KA would get a sense of a culture that is well adapted to life in the estuary. KA, its people, culture, landscape and morphology, could be such an example of human-environment interaction specified in UNESCO WHS cr.5. Preliminary findings based on fieldwork suggest that its appearance is the product of interrelationship among people and between them and the environment through time. As the process appears highly organic, a theoretical framework founded on biological systems would be appropriate.

This paper therefore aims to elucidate the underlying cultural traits that has continually reproduced the pattern, morphology and life of KA for over 500 years. This constant, which have survived and directed its evolution, is examined through the lens of biomimicry. The paper discusses the findings vis-à-vis UNESCO's WHS cr.5, including sustainability issues. 


\section{Methodology}

Biomimicry posits that sustainable solutions exist, embedded in the structure and life strategies of the diversity of organisms on Earth, because Life has existed for 3.8 billion years, surviving several cataclysmic events (Benysus, 1997). This concept is founded on organismic evolving system, which also underlies the Biosphere of Vernadsky (1988) and the self-regulating planet, Gaia, of Lovelock (1995). Capra (1996) provides a comprehensive review of systems thinking and contrasted between organismic and mechanistic models of the Earth and environment. The mechanistic system, based on physics, views the world as one that is amenable to human control. It is also vulnerable to changes caused by human agency; its survival is dependent on human management and protection. In contrast, organismic systems, modelled after living organisms and ecosystems, are capable of self-regulation, self-organisation, development, renewal and evolution, due to an inherent tendency to attain dynamic equilibrium. The difference in systems properties is due to differences in their underlying structure: relatively simple connections of parts with specific functions in machines versus complex web-like networks in organisms and ecosystems. In the organismic system perspective, Life, the sum total of all organic lifeform (including human beings) on the planet, played an active role co-evolving with the physical environment.

However, preference for the term biomimicry, rather than organismic systems, is due to the importance placed on the environment in the former; Hassan \& Yong (2019) found the environment to be a controlling factor in the morphological development of KA. In biomimicry, organisms chosen for research are those that have adapted best to the environment. Janine Benysus refers to them as "genius of place" and the mix of organisms that have developed a dynamic balance, "genus of biome" (Genius of biome 2018). Additionally, as KA is presently facing a number of sustainability issues, such as pollution, structures at risk of collapse, and fires, taking a biomimicry approach would allow the research to proceed beyond structural analysis to finding innovative solutions to these issues. In this paper, biomimetic analysis will begin with identification of the genius-of-place in the Sg Brunei estuary. Comparison is then made between how organisms and human population establish their place in the estuary and the relationships they develop in order to thrive. A good degree of congruence would indicate traits that would have prevailed through time and evolution, while deviation indicate otherwise.

Autopoiesis (Maturana \& Varela, 1980) is used to understand the process of organisation in KA. The theory was developed from the observation of living cells and how they self-maintain. The word "autopoiesis" means "self-forming". This is a trait that is ubiquitous in biological systems at all scales. Chemicals, organelles, cells, organs, organisms, biomes and ecosystems all establish boundaries and patterns on their own. The process of elements communicating, exchanging energy and material, will establish relationships and systems. Niklas Luhmann expanded the use of autopoiesis to social systems (Seidl, 2004). They are ecologies involving human organisms connected by communication, rules of engagement, and exchanges of resources, services, information and knowledge. The result of autopoiesis is distinctive patterns that have emerged as a consequence of social relationship within a particular context. The focus of autopoietic analysis is therefore (i) the nature of relationship and (ii) the pattern generated by the boundary of distinct elements.

Although the theory and practice of biomimicry (biomimetics or bionics are synonyms) is well established in architecture (Knippers et al., 2016), this paper focusses on the intangible structures that drove process and produced patterns and form in KA rather than the technical aspect of its architecture. It will pay attention to the nature of relationship among and between people and the environment. The findings are then used to determine if they reveal traits that are sufficiently unique to be considered as having heritage value as defined in UNESCO World Heritage Site selection criteria no. 5. They will also be used to address the second part of the cr.5, viz. vulnerability under the impact of irreversible change.

\section{KAMPONG AYER}

This section present details of the research context, which is also the data used in the analysis. As the environment is a key factor in biomimicry, the section will begin with a description of the salient characteristics of the $\mathrm{Sg}$ Brunei estuary, followed by that of KA and its evolution.

\section{A. Sg Brunei Estuary}

The estuary was formed when sea level rose by $100 \mathrm{~m}$ about 5,000 years ago and inundated the 
Sg Brunei valley (Yong, 2010). The estuary would have extended much further inland to the west and south, providing navigation pathways to villages and trading ports in the area as well as access to the large and important Sg Limbang catchment, which was ceded to Sarawak in 1890. An estuary is a depositional environment where sedimentation is a continuous process that progressively transform it into land over time. The wide navigation channels that had facilitated trade are now small rivers and completely filled in. The Limbang river has also been diverted from its connection to Sg Brunei $12 \mathrm{~km}$ southwest of KA to drain into the Brunei Bay $9 \mathrm{~km}$ to the southeast. This is a natural process due to mangrove-mudflat development. Presently, Sg Limbang is connected to the eastern part of KA via a small channel. Large areas of the estuary have become alluvial plain and swamps.

At KA, the settlement complex is separated into a northern and a southern part by the submerged channel of Sg Brunei. The width of the estuary is between $750 \mathrm{~m}$ and $950 \mathrm{~m}$, while the and submerged channel around $200 \mathrm{~m}$ wide. The tidal regime is predominantly diurnal and has a relatively low range of about $2 \mathrm{~m}$ (Yong, 1996). Ebb flows are stronger than flood flows and their erosive capacity is accentuated when combined with freshwater discharge from land, particularly after severe storms or a spell of wet weather. Mangroves colonise the shores, inducing mudflat development. This is a mutually reinforcing process that rapidly fill in estuaries as mangrove and mudflat advance. The process often builds up a sediment barrier thus cutting off the area behind the mangrove from the estuary, causing freshwater or mixed swamps to develop. Deeper channels and lakes cut off from the estuary would develop into peat swamps.

The wide mudflat in the southern part of KA supports larger clusters of houses. In the northern part, clusters of dwellings extend into Sg Kedayan, which drains into the Sg Brunei estuary and connects KA to the small alluvial valleys and low hills in its now highly urbanised catchment. Another smaller river system, Sg Kianggeh, which drains into the estuary $500 \mathrm{~m}$ to the east, played an important role in the transformation of KA in the period of modernisation. Construction materials were mined here in a collaboration between Chinese merchants from Singapore and local residents to build a bakut (partially constructed island) to serve as the first commercial centre in KA (Hassan \& Yong, 2019). The muddy, swampy area in between the two rivers was later developed as the urban centre under the direction of the British Resident in a programme of migrating the capital to land. In 1970, this urban centre on land, Brunei Town, was renamed Bandar Seri Begawan after the $28^{\text {th }}$ monarch, the architect of modern Brunei (Ibrahim, 1971).

Due to its location, the climate is hot and wet throughout the year. There is no distinct dry season. Annual rainfall is generally in the 3,000-4,000 $\mathrm{mm}$ range and average monthly temperature consistently around $27^{\circ} \mathrm{C}$ (Chua et al., 1987; Sandal, 1996; DEPR Brunei Darussalam, 2006). Thunderstorms are common and more pronounced during the transitional periods between the northeast (November to January) and southwest monsoons (May to September). Rainfall can be intense, and coupled with the relatively soft, geologically young sedimentary rocks (Sandal, 1996), yield large amounts of sediments, which enhances depositional processes in the estuary. Urbanisation and development in the river catchment areas further accelerated sedimentation as they promote erosion from higher storm runoff. The latter, when combined with ebb tidal current, scour the estuarine bed, which undermines the stability of the stilted settlement at KA (Yong, 2010; Zainuddin, 2021).

Storm runoff also introduces pollutants into the estuary, a negative environmental consequence of modern development. As estuaries are the meeting point between rivers and the sea, they are repositories of sediments, organic detritus, seeds, as well as pollutants. In sections where discharge and tidal currents cancel out, nutrients accumulate and contribute to primary biological productivity, which forms the base of the marine ecosystem. Estuaries are therefore rich in living resources, ranging from shellfish to crustaceans and fish, and the bounty extends into the Brunei Bay and coastal waters of Brunei. The mangroves are important habitats for spawning and juvenile marine organisms and therefore critical part of the marine ecosystems. They also important as resource base to the community, notably of building materials and food. The same rich ecosystem is also the cause of its detriment. Isopods, known locally as kapang, chew away wooden structures at the inter-tidal zone, including the stilts that prop up houses and other building structures (Zainuddin, 2021). 


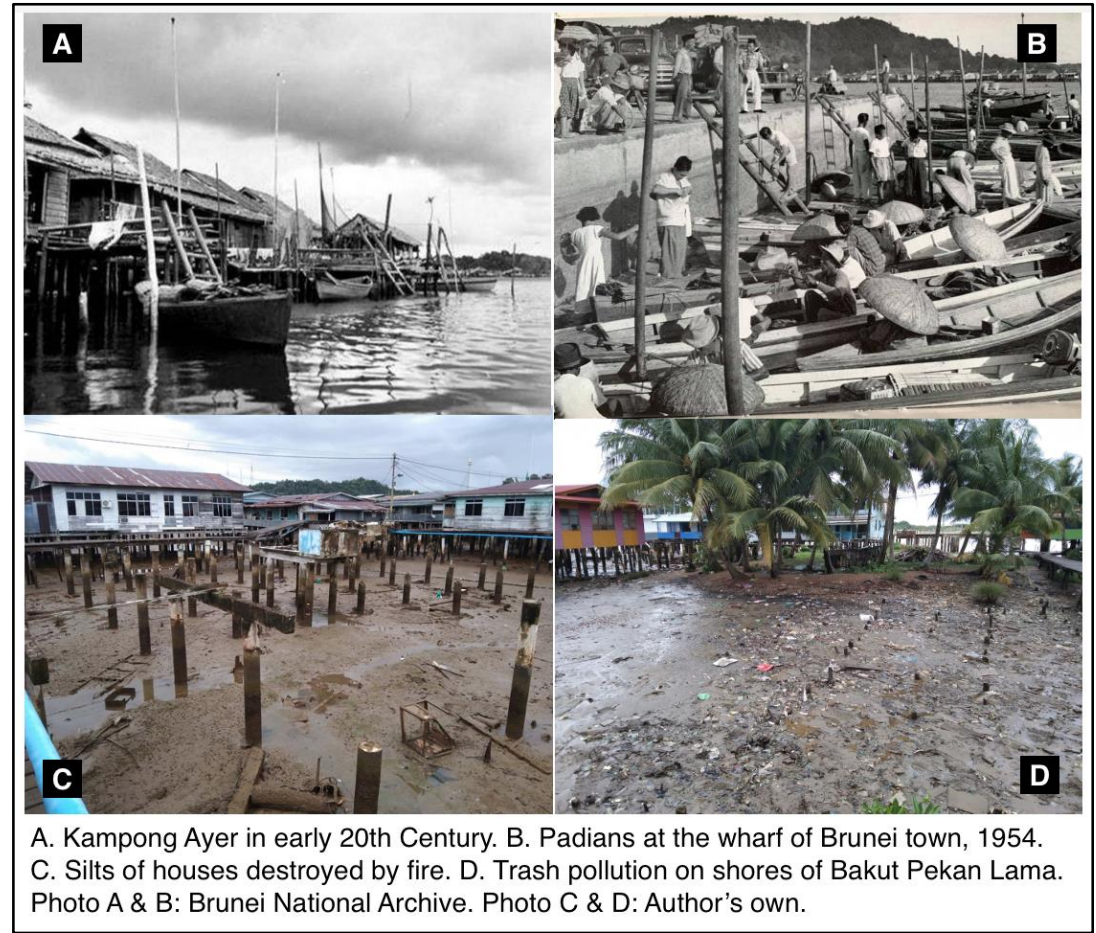

Fig. 2. Glimpses of Kampong Ayer

\section{B. Evolution of Kampong Ayer}

As pointed out at the start of this paper, the architecture of present-day KA is largely modern. The houses were built in the same location as older dwellings, replacing or modifying and adding to them in the same clusters, known as kampung (village). Some have ceased to exist, often destroyed by fire (Fig. 2C), while a few have been replaced by modern estates under renewal projects. Most however have transformed organically in response to modernisation, national development program, and natural decay. A new house in a village is often built when a family member decides to start a new family or a relative from another area moved in, including as a result of marriage. The location is decided by the head of the clan. The majority of the houses in KA today were built during the 1970s, when high oil prices provided the young nation state with much wealth, which spurred development. These modern houses survived because they were constructed using more durable materials (concrete, steel and glass) and modern architecture and construction techniques. Most were however constructed by local contractors who have acquired the knowledge from experience and knowledge shared among the community, and adapted to work within the existing culture, environmental constraints, and available resources. Adherence to technical specifications is often replaced by common sense, guidance by more experienced elders and working with what is at hand. Figure $2 \mathrm{~A}$ shows KA in the early part of the $20^{\text {th }}$ Century, before modernisation.

KA is thought to have existed since the beginning of the Brunei Sultanate in the $14^{\text {th }}$ Century. This is based the epic poem, the Shaer Awang Simaun (Ibrahim, 1970), which included a description of the floating market known as padian, which existed until the mid-20 $0^{\text {th }}$ Century (Figure $2 \mathrm{~B}$ ). This 'floating market' is mediated my women (also known as padians) selling goods in small boats. The earliest written accounts on KA were from the Europeans in the $16^{\text {th }}$ Century (Nicholl, 2007). The three most notable were by Antanio Pigafetta, who came with Magellen's expedition in 1521, Francesco de Sande, Spanish governor of Manila who attacked the Sultanate in 1578, and Admiral Oliver Van Noort, who stopped by at the end of 1600. KA prior to the Castella War of 1578 appeared to be quite different if the accounts of Pigafetta and De Sande were accurate. For example, according to the latter, the "city was very large and rich and was built over a very broad and deep river and had resembled Venice"; the building were of wood, but the houses were "excellently constructed". There was even a "very sumptuous mosque", which De Sande burned to the ground. Pigafetta's account of the houses as being built from the ground up on "tall pillars" in salt water resembles KA today. He also mentioned the padians and estimated of the size of the city at 25,000 houses, which is 10 times greater than the present number. 
By 1600, Van Noort described the town of Brunei as comprising of only about 300 houses in a swamp. The Castella War undoubtedly destroyed much of the original city, and with it, the architecture of the past. A 13-year long civil war (1660-1673) further weakened the sultanate. By the time of the arrival of the British, Brunei was near its lowest point, having lost its power and wealth, as it was cut off from the trading regime established by the Europeans (LeBlanc, 2017). It was also struggling to control piracy along its coast and unrest in various parts of its territory. The Sultanate suffered a major blow with the loss of the vast territory of Sarawak to James Brooke in 1841, who began the dynasty of White Rajahs. His successor, Charles Brooke, reduced Brunei to a tiny state split into two parts by the territory of Limbang between 1861 and 1905; the eastern region (present-day Sabah) had already been granted to Sulu Sultanate in 1658. The large island at the entrance of Brunei Bay was earlier ceded to Great Britain in 1846. In 1888, the Sultan accepted the offer to become a British Protectorate. The British Residency period started in 1906 and lasted until 1959, interrupted by the Second World War.

The first British Resident, M.S.H. McArthur, initiated a program to build a land-based economy and migrated the capital and population to land. Prior to this, a collaboration between Singaporean merchants and residents of a village with royal lineage, had established the first commercial centre in KA. The venture involved reclamation to enlarge an existing island at the southern edge of the submerged channel facing Sg Kedayan. The commercial centre in KA, known by the people as Bakut Cina (referring to the Chinese who conducted business there) was later officially named Pekan Lama (old town). The structure and organisation of KA during the first half of the $20^{\text {th }}$ Century however still exist in the memory of elderly residents and former residents, as well as in the names of the villages. It reveals a pattern of clusters within the settlement complex that is govern by social status, industry, occupation and royal lineage (Ibrahim, 1970; LeBlanc, 2017; Bakar, 2018). Blundell (1923), who lived and worked in KA during the 1900s provide an interesting and vivid eyewitness account of the 'semiaquatic life' of the people, in which 'all aspect of living has been adapted to life over water'.

Clearly, KA has evolved significantly since it was first established as a consequence of trade, war, piracy and the arrival of Europeans. Although not recorded, environmental changes were also a factor. The British has the biggest hand in the transformation. The Brunei Sultanate became a modern nation state in 1984. The process of modernisation, however, began in earnest in the late 1960s when the spike in oil prices gave Brunei the necessary funds to support development. Modernisation introduced new ideas, knowledge, culture, technologies and materials to the young nation, which was assimilated by KA and modified the cultural landscape. The process is consolidated with the institution of an education system, government and laws, and development program designed by the British. By the 1970s, KA contrasted starkly with its past form barely 25 years earlier. While it was a socially and economically vibrant place in the first half of the $20^{\text {th }}$ Century, it has become primarily a residential area, where vibrancy is provided only by the numerous motorised water taxis that criss-cross between jetties in KA and the land. KA is also saddled with the unwelcomed problem of trash and water pollution (see Fig. 2D). Some residents struggle to make a living due to the lack of economy opportunity while being burdened with the regular need to maintain the built structure, which deteriorate naturally.

\section{ANALYSIS \& DiscuSSION}

The analysis was carried out using information and knowledge accumulated from field studies and conversations with current and former residents over the past decade, some of which have been published (refer to the previous section). The findings are discussed vis-à-vis UNESCO WHS cr.5 to determine whether KA could be considered an 'outstanding example of a traditional human settlement' that is 'representative of a culture or human-environment interaction, which has become 'vulnerable under the impact of irreversible change'.

\section{A. Adaptation to the Environment}

The above-water biome in the Sg Brunei estuary is dominated by mangroves, in particular the species Sonneratia caseolaris (locally known as pidada) and Rhizophora apiculata (bakau minyak). They colonise the mudflats, building up land by inducing sedimentation and extending the mudflat further into the estuary to facilitate their propagation. This strategy not only allows it to survive in an intertidal environment, where it has to cope with periods of inundation each day, but the strategy includes altering the environmental condition to facilitate its propagation, a process that would enhance the sustainability 
of the species. The mangrove is able to achieve this feat by adapting its root structure to establish itself in the soft substrate that is periodically undermined by strong currents. The root network extents above the brackish-saline water and its dense structure enhance sedimentation, which also cause nutrients to accumulate in the vicinity of its root network, fostering the development of a vibrant ecosystem by providing food and shelter to a range of marine, mostly juvenile, organisms.

The strategies employed by families in KA resemble that of the mangrove. This is reflected in the pattern of dwellings and overall morphology of the KA complex, which follows the geomorphology of the estuarine bed. Indeed, Hassan and Yong (2019) found that families established clusters of dwellings on raised parts of the mudflat, displacing the mangroves that have colonised the tunjang (mangrove island) in the process. In an estuary, stilts are essential to elevate the living space above the highest tidal level. This is the natural strategy in an estuary with low tidal range and depth. In meso- or macro-tidal estuaries, floating habitats would have been more suitable. The stilts are installed during low tide when the ground is exposed. Mangrove seeds, similarly have better chance of establishing on exposed mudflats than when the ground is submerged. According to an interview, residents intentionally discard industrial and food waste beneath their house, as a strategy to build up land (Hassan \& Yong, 2019). From a biomimicry perspective, there is a close parallel between the human organisms and mangroves in the manner they establish themselves in the estuary, apart from the fact that the former is capable of displacing the latter but not vice-versa.

Maintaining stability is a challenge in an estuarine environment due to the occurrence of tidal currents, which moves sediments on the estuarine bed, erodes edges of bars and islands, and scour the ground around hard structures, such as stilts. Mangroves have shallow but spread-out root system to stabilise the tree. The root structure is dense and act as barriers to currents, dissipating them and promote siltation. The Rhizophora mangrove have a propped, complex network root structure. It also develops stilts that extend from their branches to the ground, where needed to shore up stability, for example, if it experiences high frequency of strong currents capable of destabilising the support structure. In the $\mathrm{Sg}$ Brunei estuary, ebb tidal currents (strongest at mid-tide) have significant erosive power, particularly when they coincide with discharge from land after a period of heavy rainfall. Stilt structures interfere with estuarine currents in similar ways to mangrove roots, generating turbulence which reduces current speeds. However, they also cause part of the current to scour the estuarine bed around stilts. Over time, some stilts would tilt, often causing the entire house to lean when a significant number of stilts have been undermined. KA residents respond to incipient tilting by installing additional stilts to prop up the house from the opposite direction, an action they refer to as menungkat. The response resembles branching in the Rhizophora roots, albeit in a much sparse way.

The older construction method that could still be seen at KA attempts to secure the stilt structure in place by adding a short cross structure known as a kancing, which is buried just below the ground. Newer stilts use the pier and beam designs with a concrete base to hold the steel rebar reinforced concrete pillar together with twelve poles hand-piled $4 \mathrm{~m}$ deep to act as anchor (Zainuddin, 2021). Although this is a clear deviation from strategies used by mangroves, i.e. mechanistic rather than organismic, the manner in which some local residents have adapted the design and installation method is highly organic, giving rise to a new occupation group of self-taught 'contractor' with their own unique bag of tools modified from the industry standard. Houses in KA also lose stilts due to bio-deterioration by kapang. This is a major problem. Residents responded to shore up the integrity of the weaken stilts in a number of ways, such as, nailing wooden planks around the tapered and riddled section, wrapping a concrete cast around damaged section, and adding a PVC tube during installation. With increasing level of modernisation, the smaller wooden stilts are replaced by larger concrete ones. KA residents readily embraced the new technology and design, adapting them to local condition. 


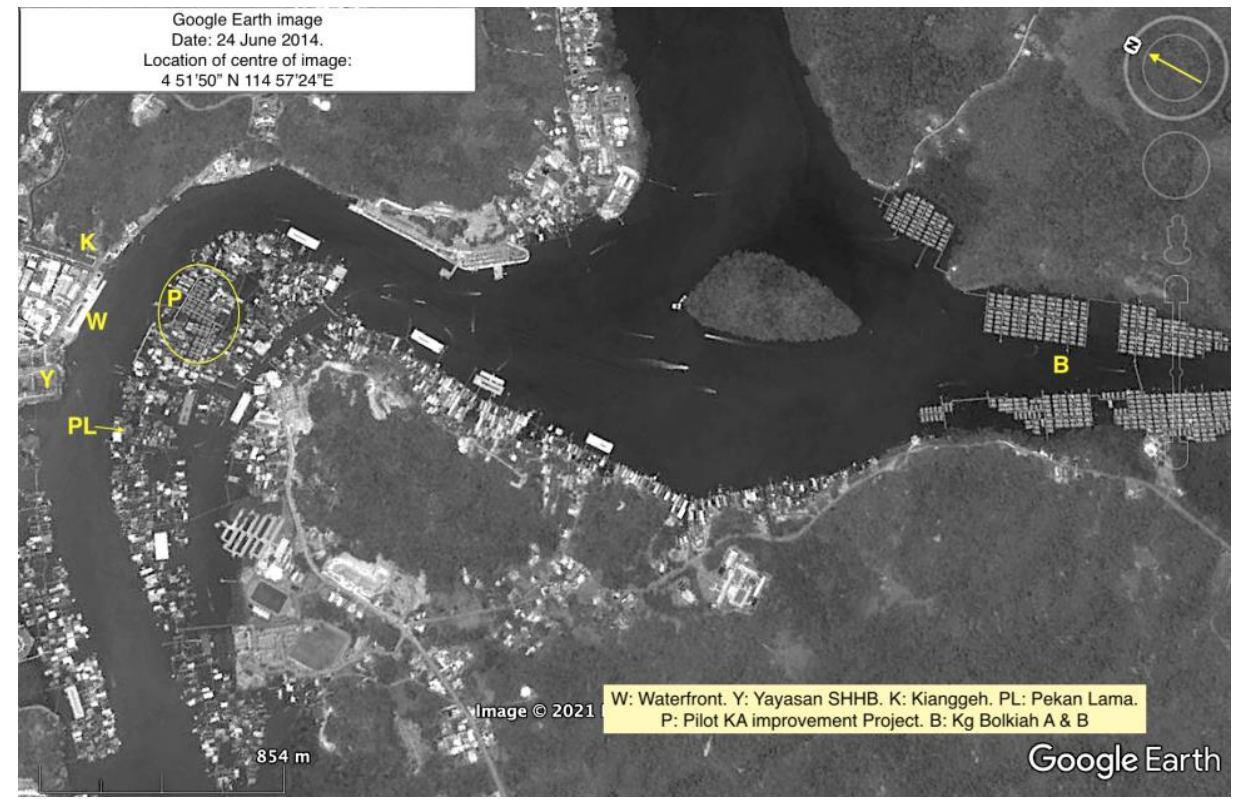

Fig.3. Organic vs. Planned Patterns.

The modern concrete stilts installed in development projects have grid pattern (refer to "P" and "B" in Fig.3). These engineered structures contrasted with the irregular clusters of KA villages. These projects has altered the morphology of KA over the past few decades, which in turn have also altered sedimentation pattern in the environment. Comparison with mangroves suggest a good degree of congruence in the strategy employed by mangroves, the genius of estuaries, and residents of KA. The main difference is that the mangrove plant has anticipated the environment before sprouting from the seed because the knowledge is embedded in its genes. Its structure and response are therefore preprogrammed to thrive in an estuarine environment. In contrast, the human organism's response is an innate instinct of living organisms, which is shares with other lifeforms as a consequence of the evolution of Life. The residents thus have a time to learn and evolve over a relatively short period of 500-600 years. As a living organism, the mangrove tree will add more stilts and increase the size of older stilts to support the above-ground structure as it grows. In KA, house have also increased in size and considerably in weight due to modernisation, coupled with affluence brought about by oil wealth. Details of this transformation during the $20^{\text {th }}$ Century are provided by LeBlanc (2017). The increase in house size is supported by a concomitant increase in the number of stilts, but of the same design and dimensions, following engineering design standard and practice.

\section{B. Organisation, Pattern and Relationship}

Self-organisation is a property of organismic systems. Organic development reflects this property of the people and environment as an interconnected, interacting assemblage, when viewed as a system. In contrast, mechanistic systems are designed and built by external agency based on modern scientific and engineering perspective of the world. In an organismic system, patterns and structures are outcomes of complex interaction between and among people and environment over a period of time. Distinct patterns are indicative of dynamic equilibrium condition, where people have established a culture that is in balance with environmental dynamics. At KA, this means living over a water environment where: water level rises and fall in level each day; stability of the stilted structures they erected will be undermined by currents; wooden structures susceptible to deterioration and fires; and where space for social interaction and food production is scarce. The fact that the water-based settlement has existed for at least 500 years suggest that the inhabitants have developed a culture that is in dynamic equilibrium with the estuary. Blundell (1923) capture this in his book, "city of many waters" based on his personal experience and observation as a foreigner.

KA is not a single village. This misconception is due to the name given when the British organised the administrative boundary during the early years of modernisation (Ibrahim, 1971). KA is a complex of villages, or 'wards', given that they are closely spaced clusters. Each cluster developed organically by clans, very much in an autopoietic manner. Familial relationships, many of which are strengthened 
by occupation, cottage industry and social status, establish the pattern and boundary of each cluster. LeBlanc (2017) provided some examples of the clustering process due to kinship and hierarchy in this thesis on the urban morphology of KA; it must be noted that he did not associate them to the concept or autopoiesis. LeBlanc concluded that the morphology of KA reflects the social relations, and the relationship between the monarch and his subjects. Indeed, this is reflected in the spatial pattern, where relationship and hierarchy is reflected in proximity to the location of the palace. Clans that engage in fishing, gathering construction materials, and other primary occupation are located at the edges of the settlement complex, while craftsmen and traders are found closer to the centre, where families with royal lineage, nobles and religious leaders have their wards (Ibrahim, 1971). This distribution pattern of wards is however also controlled by the physical environment, notably the location of raised land on the mudflats.

The organic nature of development is evident in the irregular clustering and personalised character of dwelling, which reflects the occupants and their relationship to their surroundings. This proxemic nature is reflected in the traditional measures of dimensions used in KA, such as dapa (equivalent to the length of stretched out arms horizontally from the fingertips of one arm to the fingertips of the other, usually of the wife/mother) and sirang (twice the length of one dapa). The structure of the house is built around the people, in contrast to modern housing, where houses are designed and built for occupation by people. Pre-modern architecture of KA houses has a strong proxemic control, a trait which is evident in the tendency of recipients of houses in the national housing scheme to modify their house soon after occupation (Hassan \& Yong, 2018). Although the houses in KA today have modern designs and largely built using modern construction materials, there is stark contrast between them and houses built under renewal projects both in term of house design and pattern. In Figure 3, the grid pattern of the Kampong Bolkiah A and B project (labelled "B") and Project to upgrade KA ("P") stands out from the less organised pattern of the surrounding villages. The houses in these development projects are uniform in structure, material used, and even colour, in contrast to the personalised dwellings in the surrounding with strong proxemic character. They also possess many make-shift patch-up materials and structures as evidence of constant effort to preserve the house from collapse. Residents readily scavenge materials from collapsed or abandoned houses to shore up their own, i.e. recycling, which is indicative of organismic process.

The linkages to location, occupation/industry, kinship and monarch in present-day KA reside mainly in the mind of a small group of residents and former residents. The structure of houses, while possessing proxemic characteristics, have assimilated modern designs and materials to an extent that they bear little semblance to their earlier versions, even barely half a century ago. The industrial and economic structures that have survived for hundreds of years have ceased to exist, while the new structures to support tourism have not been able to consolidate. The cultural structures exist somewhat like a ghost - invisible, unclear if they are real except only to a small group, but generally accepted as the place where the event happened in the past. A negative effect of modernisation, however, is that it introduced the man-above-nature paradigm into the national development program, which resulted in large-scale changes to KA and its environment, without considering their impacts. Consumption of modern non-biodegradable materials also add to trash pollution, exacerbated by the changes to the stilt design and their greater numbers, which promotes trash accumulation.

\section{Discussion on Heritage \& Conservation}

With reference to UNESCO WHS cr.5, KA would appear to be representative of a culture and human interaction with the environment, in this case, a tropical estuary, and KA has indeed become vulnerable under the impact of irreversible change. With regards to the last point, the fact that KA, which was a vibrant, thriving urban centre in a water environment, is now a deteriorating settlement with pockets of renewal bereft of an economy and employment opportunity, has made it vulnerable as a historic site. Persistent trash and water pollution and susceptibility to fire and collapse has also raised calls for wholesale redevelopment, which would certainly obliterate whatever is left of its fading heritage. History likened KA to Venice. Present-day KA however is a vestige of its past glory, and is certainly under threat of being lost, assimilated in the urban fabric of modern Brunei. Whether it is an 'outstanding example' is debatable. However, biomimetic analysis reveals interesting intangible structures in the relationships among people and between them and the physical environment, which have prevailed until the dawn of the modern era. From this perspective, if such relations and structures 
are presented in clear and experiential ways, they might sway argument towards its uniqueness, and hopefully, compelling enough for it to be regarded as an outstanding example.

Regarding its conservation, this paper will not discuss the possible ways and means; a paper proposing the development of a heritage industry as a viable strategy by Izni Azarie Noor Azalie \& Yong is currently under review. This paper will only focus on conservation of the environment, both built and natural, as this is a natural progression of a biomimetic analysis. The research has improved understanding of the environment and relationship between people that reside in it. It has also identified the most successful organism in the estuary, the mangrove, particularly the Rhizophora or bakau, which has become more dominant with changes due to development in the catchment. The application of biomimicry will therefore focus on the design and strategies employed by this genius of the estuarine environment. It will address two conservation issues: (i) stability of built structure, and (ii) alleviating pollution.

\section{1) Structure Stability}

Built structures in the Sg Brunei estuary are subjected to currents that could undermine their stability over time. The modern solution to stability is to have larger, harder stilt with deeper anchor. Thus, the stilts of KA houses evolved from single bakau or nibong pole, to timber beam and later, concrete with steel rebar and bakau anchor. Rhizophora mangroves have a prop root system that grows in thickness, complexity and extent concomitant with its development in size and maturity. The mangrove root is designed to provide it with the best chance of thriving, not merely surviving, in an estuarine environment right from the start. A stilt design solution for stability would therefore be one that resemble the root of the Rhizophora mangrove. This could be a cone/ block, instead of a pillar, of mesh structure, which could be designed to allow for augmentation from above to increase the density and thereby, strength of the support structure. To ease installation, they could be prefabricated or 3D printed on site, due to the limited time for construction, as work is best done during low tide when the ground is exposed. Further research is needed to identify and produce the most suitable material and to refine the design.

Another design solution would be to link the support structure by clustering. As mangroves grow and develop, the roots of individual trees intermesh to form a larger complex that support and enhance the stability of the whole cluster. This would also foster sedimentation, resulting over time in building land and raising the mangrove above the tidal level, away from erosive currents. Presently, individual KA houses are only tenuously connected via their links to the walkways that straddle the settlement complex. Drawing from the development strategy of mangroves, the support structures of individual houses could be interconnected by intermeshing them deliberately to strengthen the stability of the cluster rather than keep individual houses separated. This could be done by combining the structure with others to integrate multiple functions within the same structure, for example, sewage and trash management, and or food production. Natural structures are always multifunctional in design. Figure 4 shows the dense network structure of the Rhizophora mangroves.

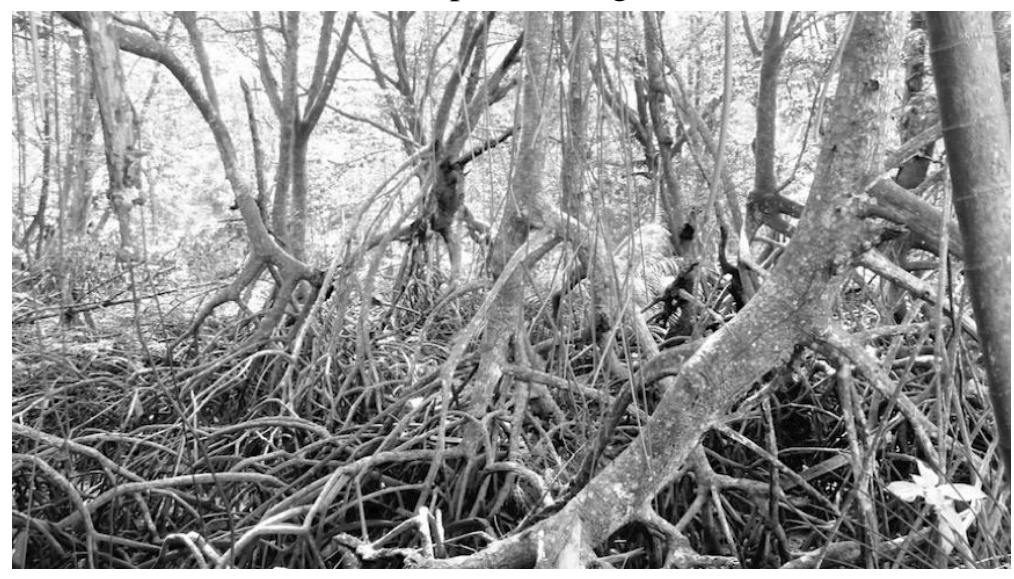

Fig. 4. Root Structure of the Rhizophora Mangrove

\section{2) Pollution Alleviation}

Modernisation, fuelled by affluence from oil wealth, has given rise to pollution in KA in two main ways: (i) higher rates of consumption and (ii) non-biodegradable wastes. The culture of disposing waste 
to the surrounding is ecological when the waste is biodegradable. However, it becomes pollution when it is non-biodegradable and discarded at a rate greater than the environment's ability to assimilate them. As a depositional environment, the $\mathrm{Sg}$ Brunei estuary is also a repository for wastes discharged from the urbanised catchment. Moreover, the larger number of silts in KA to support larger and heavier houses as well as walkways and jetties also serve to attract and accumulate floatable trash. Despite efforts by authorities and residents to rid the environment of it, trash has remained a persistent problem. Meanwhile, direct discharge of waste water has given rise to water pollution (DEPR Brunei Darussalam, 2006). This is exacerbated by the restricted tidal flushing in this section of the estuary (Currie, 1979).

How would mangroves deal with trash? As explained above, the roots system induced sedimentation, which builds up land over time. Trash and pollutants would be incorporated into the mudflat to become part of the substrate that raises the level of the ground. This strategy increases the stability of the mangrove and serves as a filtering system of storm discharge by trapping sediments and pollutants, thus protecting water quality in the estuary. In contrast, modern strategy involves collecting and removing trash from the KA environment and burying them at another location (landfill). A biomimetic strategy would be to leverage on the effect of mangrove-like stilts to draw floatable trash towards them so that trash could be 'harvested' by diverting them into a collector. The waste accumulated could then be compacted and buried on site. The process would also raise the level of the ground, creating land within the estuary. Those who believe that KA should always be in water is unaware of the natural dynamic of estuaries and culture of KA. Such a trash collection-burial system could be designed and incorporated into the mangrove-type stilt structure, combining alleviation of trash pollution with enhancing stability of built structure.

The primary cause of water pollution in KA is direct discharge of raw sewage from the majority of homes. Only houses constructed as part of renewal projects have vacuum toilet systems. Installing a modern sewage network in KA was said to be problematic and costly. In nature, organic waste is just part of the ecological loop in an ecosystem. There is no waste in an ecosystem and therefore no need for waste management. In a biomimetic design, the recycling loops could be installed to intercept sewage discharge and connect it to a regenerative system, such as a food production or energy generation unit. A distributed modular design, i.e., installing units to serve small clusters, would be less problematic and less costly. A regenerative unit would also add value and provide services or resources to each group of homes. As with the other proposals, further research is needed on the details. Indeed, ecological designs could be used to address a range of sustainability problems while enhancing quality of life and vitality in a self-sustaining manner. A biomimetic design is an ecological design that is tailored to the specific environmental condition and dynamics of the place, modelled after the most successful organisms that thrive there.

\section{CONClusion}

The paper use biomimicry to show that the heritage value of the historic KA lies in the intangible structures that govern relationships among people and between people and environment, rather than in physical attributes of the built complex. It hopes to show that, from biomimetic analysis, they reveal a human-environment relationship that could be considered outstanding because it has prevailed for over half a millennium and that it is presently vulnerable to the impact of irreversible change due to modernisation (Centre, The criteria for selection cr.5). The study found a good degree of congruence between the relationship between people and the estuarine environment with that of mangroves, which has adapted to thrive in estuaries. This is reflected in the highly organic manner in which residents construct their dwellings and response to environmental dynamics to sustain their homes. The clustered pattern is an outcome of this organic, self-forming or autopoietic process produced and sustained by relationships founded on kinship, social hierarchy, industry and commerce, Islamic monarchy, as well as the physical environment. Modernisation, particularly following World War II, has replaced much of the cultural structures with imported ones and given rise to conditions that threatened to obliterate the heritage value contained in KA as well as its environmental sustainability. Biomimicry was also used to identify potential solutions to the sustainability of the built and natural environment.

The paper concludes that the true structure of KA is more apparent from a biomimetic perspective, and that it reflects a unique culture that have been established by organismic interaction between a people and the estuary in which they have lived for more than 500 years. This, it is hope, shows that KA 
is an outstanding example of a unique culture and relationship between people and environment, which has become vulnerable to impacts from irreversible change brought about by modernisation and now, globalisation. The paper proposes that sustainable solutions from biomimicry be considered.

\section{REFERENCES}

Bakar, H. T. A. (2018). The residents of Kampong Ayer, 1906-1940: the activities of Pengalu, Padian and Handiwork. Tawarikh: International Journal for Historical Studies, 9 (2), 151-158.

Benyus, J. (1997). Biomimicry: Innovation inspired by nature. New York: Harper Collins.

Blundell, P. (1923). The City of Many Waters. London: Arrowsmith.

Capra, F. (1996). The Web of Life: A New Scientific Understanding of Living Systems. New York: Anchor

Centre, U. N. E. S. C. O. W. H. (n.d.). The criteria for selection. UNESCO World Heritage Centre. https://whc.unesco.org/en/criteria/.

Chua, T. E., Chou, L. M. \& Sadorra, M. S. M. (1987). The coastal environmental profile of Brunei Darussalam: resource assessment and management issues. Brunei Darussalam: Brunei Department of Fisheries and International Centre for Living Aquatic Resources Management.

Currie, D. (1979). Some aspects of the hydrology of the Brunei Estuary. Brunei Museum Journal, 6, 199-239.

Department of Environment, Parks \& Recreation (DEPR) Brunei Darussalam (2006). Brunei Darussalam State of the Environment Report. Bandar Seri Begawan: Brunei Darussalam Department of Environment, Parks \& Recreation.

Genius of biome. Biomimicry 3.8. (2018, April 3). https://biomimicry.net/the-buzz/resources/genius-of-biome/.

Hassan, N. H. \& Yong, G. Y. V. (2018). A Vision in Which Every Family Has Basic Shelter, in Holzhacker, R. \& Agussalim, D. (eds), Sustainable Development Goals in Southeast Asia and ASEAN (9 ${ }^{\text {th }}$ ed. , pp. 190-209). Brill.

Hassan, N. H. \& Yong, G. Y. V. (2019). The cultural value of bakuts in Kampong Ayer, Brunei Darussalam. South East Asia: A Multidisciplinary Journal, 19, 47-63.

Ibrahim, H. A. L. H. (1970). Padian: Its Market and the Women Vendors. Brunei Museum Journal, 2(1), 39-51.

Ibrahim, H. A. L. H. (1971). Variations and Changes in the Names and Locations of the Wards of Kampong Ayer Over the Last Century. Brunei Museum Journal, 2(3), 56-73.

Knippers, J., Nickel, K. G., \& Speck, T. (2016). Biomimetic Research for Architecture and Building Construction: Biological Design and Integrative Structures. Cham: Springer.

LeBlanc, R. (2017). A deleuze theory of urban morphology: Brunei Water City (unpublished PhD thesis). Victoria University.

Lovelock, J. (1995). Gaia: A New Look at Life on Earth. Oxford University Press.

Maturana, H. R. \& Varela, F. J. (1980). Autopoiesis and Cognition: The Realization of the Living. Dordrecht: Reidel Publishing

Nicholl, R. (Ed.) (2007). European Sources for the History of the Sultanate of Brunei in the Sixteenth Century. Muzium Brunei.

Sandal, T. S. (Ed.) (1996). The geology and hydrocarbon resources of Negara Brunei Darussalam. Seria: Brunei Shell Petroleum.

Seidl, D. (2004). Luhmann's theory of autopoietic social systems. Munich Business Research, LudwigMaximilians-Universität München

Vernadsky, V. I. (1988). The Biosphere. Translated by Langmuir, D.B. Copernicus.

Yong, G. Y. V. (1996). Coastal Geomorphology in Negara Brunei Darussalam, in Sirinanda, K.U, and Michael, P. (ed.). Geography at Universiti Brunei Darussalam (57 - 62). Brunei Darussalam: Universiti Brunei Darussalam.

Yong, G. Y. V. (2010). Brunei (Negara Brunei Darussalam). In Bird, E., Encyclopedia of the World's Coastal Landforms (pp. 1142 - 1143). Springer.

Zainuddin, N. H. H. (2021). Evolution of Stilts in Kampong Ayer. Brunei Museum Journal, 95-110. 